\title{
Something old, something new: Marrying 2 approaches to resect an ectopic parathyroid adenoma
}

\author{
Isidore Dinga Madou, MD, ${ }^{\mathrm{a}, \mathrm{b}}$ Glenda G. Callender, MD, ${ }^{\mathrm{a}}$ and Anthony W. Kim, MD, ${ }^{\mathrm{b}}$ New Haven, Conn
}

\footnotetext{
From the ${ }^{\mathrm{a} S e c t i o n}$ of Endocrine Surgery; and ${ }^{\mathrm{b}}$ Section of Thoracic Surgery, Department of Surgery, Yale School of Medicine, New Haven, Conn.

Disclosures: Authors have nothing to disclose with regard to commercial support.

Received for publication May 16, 2015; revisions received Aug 22, 2015; accepted for publication Sept 28, 2015. Address for reprints: Anthony W. Kim, MD, Section of Thoracic Surgery, Yale School of Medicine, 330 Cedar St, BB 205, New Haven, CT 06520 (E-mail: anthony.kim@yale.edu).

J Thorac Cardiovasc Surg 2016;151:e33-4

$0022-5223 / \$ 36.00$

Copyright $(2016$ by The American Association for Thoracic Surgery

http://dx.doi.org/10.1016/j.jtcvs.2015.09.105
}

Ectopic middle mediastinal parathyroid adenoma is rare, and it is often associated with persistent hyperparathyroidism. ${ }^{1}$ The transpericardial surgical approach to the middle mediastinum, for the resection of an ectopic gland in this location, is infrequently utilized. ${ }^{2}$ Coupling the transpericardial approach with intraoperative parathyroid hormone (IOPTH) monitoring was crucial to establishing an intraoperative biochemical cure.

\section{CASE}

A 55-year-old woman underwent failed parathyroidectomy at another institution, during which 2 normal parathyroid glands were identified in her neck (2 normal glands on the right; 1 normal gland on the left). At that time, the left thymus was removed transcervically, but the missing parathyroid gland was not within it. Serum calcium and intact parathyroid hormone (PTH) levels remained

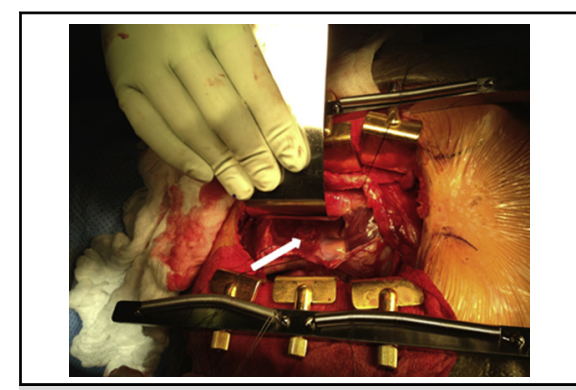

A tan-colored nodule posterior to the ascending aorta and adjacent to the trachea.

\section{Central Message}

This case highlights the crossover between endocrine and thoracic surgery in the management of middle mediastinal parathyroid adenomas.

See Editorial Commentary page e35.

elevated postoperatively, and her symptoms of fatigue, memory loss, insomnia, and leg cramps remained unchanged. Her past history was significant for Hodgkin's lymphoma treated with mantle radiation and left breast cancer requiring reconstruction using a deep inferior

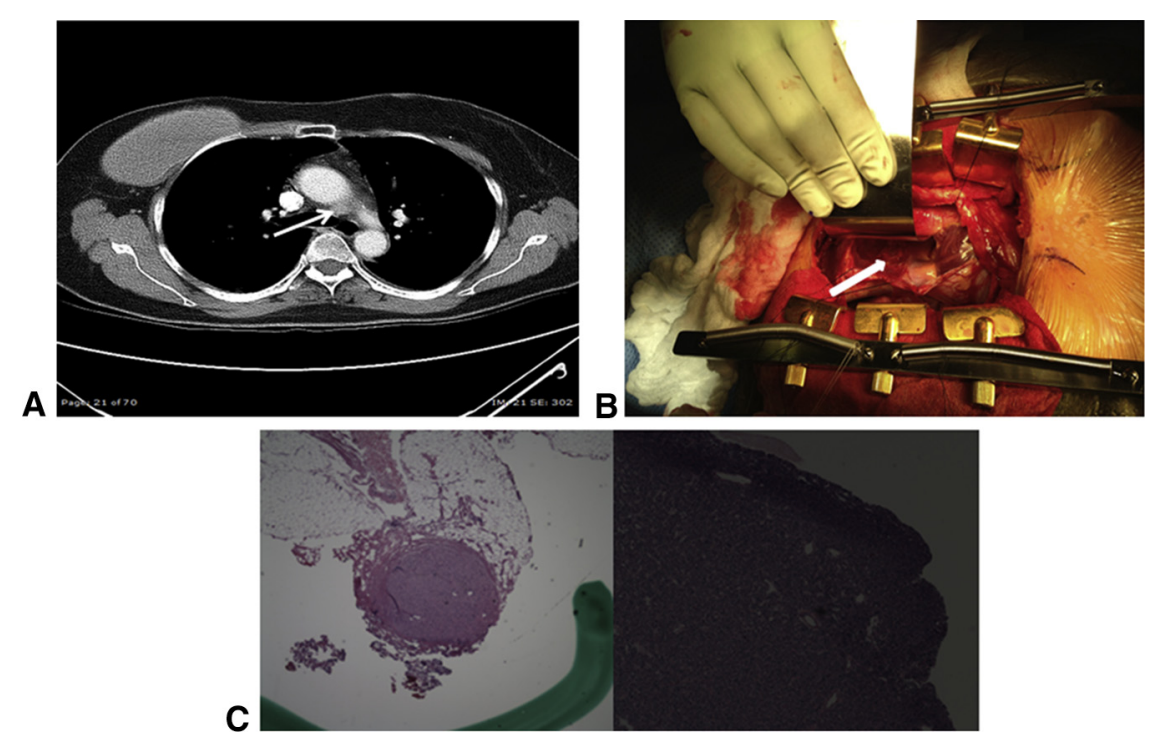

FIGURE 1. A, A computed tomography angiogram of the chest, demonstrating a soft-tissue nodule in the posterior subaortic space of the middle mediastinum, measuring $9 \times 4 \mathrm{~mm}$. B, Intraoperative image confirming that the lesion was located in the medial aspect of the middle mediastinum in the posterior subaortic space. C, Enlarged, cellular, benign-appearing parathyroid gland weighing $588 \mathrm{mg}$ and measuring $1.3 \mathrm{~cm}$ in its greatest dimension. 
TABLE 1. Intraoperative parathyroid hormone assay results

\begin{tabular}{lcc}
\hline $\begin{array}{c}\text { Time from } \\
\text { resection (min) }\end{array}$ & $\begin{array}{c}\text { IOPTH (Reference: } \\
\mathbf{1 0 - 6 9} \mathbf{~ p g / m L})\end{array}$ & $\begin{array}{c}\text { Decrease from } \\
\text { baseline (\%) }\end{array}$ \\
\hline Baseline-preoperative* & 163 & - \\
0 & 111 & 68 \\
5 & 53 & 32 \\
10 & 33 & 20 \\
15 & 28 & 17 \\
20 & 26 & 16 \\
\hline
\end{tabular}

*Drawn immediately before surgical manipulation. IOPTH, Intraoperative parathyroid hormone.

epigastric perforator flap supplied by the internal mammary artery in the second and third intercostal spaces.

Physical examination was unremarkable. Laboratory studies revealed a serum calcium level of $13 \mathrm{mg} / \mathrm{dL}$ (normal: $8.8-10.2 \mathrm{mg} / \mathrm{dL}$ ), an intact PTH level of 308 $\mathrm{pg} / \mathrm{mL}$ (normal: 10-69 $\mathrm{pg} / \mathrm{mL}$ ), and a 25 -hydroxy-vitamin D level of $44 \mathrm{ng} / \mathrm{mL}$ (normal: $30-100 \mathrm{ng} / \mathrm{mL}$ ). A computed tomography (CT) angiogram of the chest demonstrated a $9 \times 4 \mathrm{~mm}$ soft-tissue nodule in the posterior subaortic space of the middle mediastinum (Figure 1, A); neck imaging, including ultrasound, sestamibi-single-photon emission computed tomography, and 4-dimensional CT of the neck (a CT modality utilizing the 3 dimensions of space, along with the timing of uptake and washout of intravenous contrast, to identify enlarged parathyroid glands) ${ }^{3}$ was negative.

After median sternotomy, the anterior pericardium overlying the base of the aorta was opened. The posterior pericardium was opened through dissection of the space between the superior vena cava and the aorta. A tan-colored nodule posterior to the ascending aorta, adjacent to the trachea was resected (Figure 1, B). The IOPTH level decreased to $16 \%$ of baseline within 20 minutes, confirming intraoperative biochemical cure and precluding the need for further exploration (Table 1). Pathology demonstrated a benign parathyroid adenoma weighing $588 \mathrm{mg}$ (Figure 1,C). The patient's 2-week postoperative serum calcium level was $8.3 \mathrm{mg} / \mathrm{dL}$, and the intact PTH level was $66 \mathrm{pg} / \mathrm{mL}$, both being expected values confirming early postoperative biochemical cure.

\section{DISCUSSION}

The middle mediastinal location accounts for $1 \%$ to $5 \%$ of ectopic mediastinal parathyroid glands and $0.24 \%$ of all parathyroid adenomas. ${ }^{1,4}$ Mediastinoscopy was considered for this patient, but was thought to be unfavorable, given her prior neck exploration with transcervical thymectomy and mantle radiation. A thoracoscopic approach was thought to be inadequate given the target lesion's location in the medial aspect of the subaortic space. A Chamberlain procedure was deemed undesirable because of the patient's prior left deep inferior epigastric perforator flap reconstruction, which utilized intercostal spaces 2 and 3 for the free flap vascular pedicle to the internal mammary artery. A transpericardial approach coupled with IOPTH monitoring was considered the optimal approach.

Intraoperative parathyroid hormone sampling takes advantage of the short half-life of PTH in patients who have normal renal function (1.68-4 minutes) and allows for confirmation of biochemical cure after parathyroidectomy. In the hands of an experienced endocrine surgeon, targeted parathyroidectomy offers outcomes equivalent to or better than bilateral neck exploration (in cure rate, operating time, length of hospital stay, complication rate, and cost). ${ }^{5}$ In our institution, IOPTH levels are measured prior to parathyroidectomy (baseline), and after parathyroidectomy, at 5-minute intervals for approximately 20 minutes.

The surgeon evaluates the slope of the curve of PTH decline to assess cure, with more-accurate results than the classic "Miami criteria"- decline by $\geq 50 \%$ from baseline and into the normal range by 10 to 15 minutes after resection. ${ }^{3}$ If biochemical cure is not reached after resection of a target lesion, further exploration is usually warranted; in this case, the increased risk of reoperative neck surgery would not be recommended in the absence of an imaged target in the neck. If the resected lesion had not proven to be a parathyroid adenoma, no plan was in place to re-explore the neck. The patient would have proceeded electively to an advanced imaging modality, such as selective venous sampling.

In conclusion, the transpericardial approach with IOPTH allowed for biochemical confirmation of intraoperative cure after resection of a middle mediastinal ectopic parathyroid adenoma. This combination was crucial given the magnitude of the surgical approach and the prior neck surgery, which precluded blind neck re-exploration.

\section{References}

1. Kim AW, Detterbeck FC. Surgery of the thyroid and parathyroid glands. In: Oertli D, Udelsman R, eds. Surgical Approaches to Mediastinal Parathyroid Glands. 2nd ed. Berlin: Springer; 2012:495-504.

2. Arnault V, Beaulieu A, Lifante JC, Sitges Serra A, Sebag F, Mathonnet M, et al. Multicenter study of 19 aortopulmonary window parathyroid tumors: The challenge of embryologic origin. World J Surg. 2010;34:2211-6.

3. Udelsman R, Donovan P, Shaw C. Cure predictability during parathyroidectomy. World J Surg. 2014;38:521-4.

4. Ali M, Kumpe DA. Embolization of bronchial artery-supplied ectopic parathyroid adenomas located in the aortopulmonary window. J Vasc Interv Radiol. 2014;25: 138-43.

5. Udelsman R, Lin Q, Donovan P. The superiority of minimally invasive parathyroidectomy based on 1650 consecutive patients with primary hyperparathyroidism. Ann Surg. 2011;253:585-91. 